\title{
CONTAÇÃO DE HISTORIAS: UM RECURSO PEDAGÓGICO NO DESENVOLVIMENTO DA LINGUAGEM
}

\author{
Aline Macedo de Souza, Odair Benedito Francisco \\ Universidade do Oeste Paulista - UNOESTE, Presidente Prudente, SP. E_mail: alitchetis@hotmail.com, \\ odair272@yahoo.com.br.
}

\section{RESUMO}

Esta pesquisa discutirá sobre a importância do ato de contar histórias no espaço da educação infantil, realizando uma reflexão sobre possíveis estratégias que auxiliam na prática da contação de histórias. Como objetivos destacamos: levantar informações sobre como surgiu a contação de histórias, dissertar sobre a importância da literatura na Educação Infantil e descrever estratégias para o trabalho com a contação de histórias. A metodologia usada foi levantamento de dados encontrados na literatura já existente, por meio de pesquisas bibliográficas. Concluímos que a literatura juntamente com a prática da contação de histórias, representa várias possibilidades, desenvolvendo não somente a linguagem, como também auxiliando na elaboração e produção de bons textos, criando possibilidades pedagógicas diversificadas, criativas e estimulantes para desenvolver a atenção e a concentração dos alunos.

Palavras-chave: Contação de histórias, Estratégias, Linguagem.

\section{STORYTELLING: AN EDUCATIONAL RESOURCE IN LANGUAGE DEVELOPMENT}

\begin{abstract}
This research has the purpose of discuss the importance of the act of storytelling on children's educational environment, conducting a reflection on possible strategies that assist in the practice of storytelling. Objectives include as follow: raising information on how the storytelling was created, the lecture of the importance of literature in early Childhood Education as also describe some strategies for working with the storytelling. The methodology used was based on data collection found in existing literature through bibliographics researches. In conclusion, we understand that the literature in connection with the practice of storytelling provides several possibilities such as developing not only the language but also assisting in the elaboration and production of well developed texts, creating pedagogical diversity possibilities, in a creative and stimulating way in order to develop the student's attention and concentration.
\end{abstract}

Keywords: Storytelling, Strategies, Language.

\section{INTRODUÇÃO \\ O presente trabalho discute a importância do ato de contar histórias no espaço da educação infantil, realizando uma reflexão sobre possíveis estratégias que auxiliem nesta prática em sala de aula. \\ Segundo Busatto (2003), a contação de histórias é uma atividade necessária e imprescindível no processo de desenvolvimento da criança, pois ela ajuda na formação da personalidade humana e, por isso, deve ser desenvolvida e valorizada no}

meio escolar, a fim de potencializar a linguagem e diferentes outras habilidades, favorecendo também o processo de ensino e aprendizagem e socialização da criança.

Este artigo aborda como o ato de contar histórias na educação infantil favorece a aprendizagem, tendo a intenção de analisar como o professor pode inseri-lo nas suas propostas e planos de aula com a intenção de despertar o interesse dos seus alunos para este tipo e atividade. 
A escolha dessa temática justifica-se por se tratar de um assunto que sempre se faz presente nas práticas da educação infantil, sendo um elemento facilitador para abordar diferentes temas nessa etapa de escolarização.

Coelho (1984) disserta que:

[...] a história é importante alimento da imaginação. Permite a o uso da linguagem, favorecendo a aceitação de situações desagradáveis, ajuda a resolver conflitos. Agrada a todos, de modo geral, sem distinção de idade, de classe social, de circunstância de vida. Descobrir isso e praticá-lo é uma forma de incorporar praticidade à vida, [...] (COELHO, 1984, p. 12).

Como objetivos do presente trabalho destacamos: levantar informações sobre o surgimento da contação de histórias, descrever estratégias para o trabalho com elas e dissertar sobre a importância da literatura na Educação Infantil.

Para tanto, parte-se da hipótese de que será possível um trabalho significativo, utilizando-se da contação de histórias com as crianças da educação infantil desde que seja adotada uma concepção pedagógica que as considere como autônomas, criativas e construtoras de conhecimento.

\section{METODOLOGIA}

O levantamento de informações para a elaboração deste trabalho, baseou-se em um arcabouço teórico referente ao estudo da contação de histórias a partir da análise de material bibliográfico impresso e digital da biblioteca virtual Scielo que dispõe de pesquisas científicas na área do conhecimento específica, além dos documentos publicados pelo portal do Ministério da Educação (MEC).

$$
\text { Esta pesquisa bibliográfica }
$$
qualitativa, de caráter investigativo, culmina com as ideias de Cervo, Bervian e Silva (2007), em que

$$
\begin{aligned}
& \text { a pesquisa bibliográfica } \\
& \text { procura explicar um } \\
& \text { problema a partir de } \\
& \text { referências teóricas } \\
& \text { publicadas em artigos, } \\
& \text { livros dissertações e }
\end{aligned}
$$

teses. Pode ser realizada independentemente ou como parte da pesquisa descritiva ou experimental. Em ambos os casos, busca-se conhecer e analisar as contribuições culturais ou científicas do passado sobre determinado assunto, tema ou problema (CERVO; BERVIAN; SILVA, 2007, p. 60).

Desse modo, o artigo está dividido em três capítulos, sendo que no primeiro apresentamos o levantamento de informações sobre como surgiu a contação de histórias no âmbito da educação infantil. O segundo capítulo traz a importância da contação de histórias na educação, mais especificamente na Educação Infantil, com crianças de 02 e 03 anos. Já no terceiro capítulo apresentamos as estratégias para as salas de aula que auxiliam na contação de histórias. Portanto, descrevemos algumas atividades que possam contribuir tanto para as professoras da sala comum, ou seja, aquelas sem formação específica em literatura, quanto para os professores que são habilitados e especialistas em contação de histórias.

Nesse sentido, por ser uma pesquisa qualitativa, Cruz (2011) destaca que este tipo de pesquisa:

é basicamente aquela que
busca entender um
fenômeno específico em
profundidade. Ao invés de
estatísticas, regras e
outras generalizações, ela
trabalha com descrições,
comparações,
interpretações
atribuição de significados
possibilitando investigar
valores, crenças, hábitos,
atitudes e opiniões de
indivíduos ou grupos
(CRUZ, 2011, p. 21).

A partir disso, a pesquisa adquire um efeito significativo, por tratar do tema central no âmago da sociedade e de seus indivíduos, buscando relações entre teoria e prática para que seja possível uma ressignificação possível de contextos escolares no que se refere às 
atividades de contação de histórias na Educação Infantil.

\section{Surgimento da Contação de Histórias}

$\mathrm{O}$ ato de contar e recontar histórias são uma ação que ocupa a mente humana há muitos e muitos anos. Pessoas de vários lugares do mundo contam histórias para se descontraírem, passarem conhecimento, ou para simplesmente não sentirem o tempo passar. Até mesmo antes da invenção da escrita pela humanidade, já se contavam histórias. As histórias foram passadas de geração em geração e hoje são relembradas em livros, filmes na televisão e até mesmo nos jogos. Mesmo com toda a tecnologia, a tradição do conto oral ainda se mantém.

Definindo "contação de histórias", Torres e Tettamanzy (2008) afirmam que:

$$
\begin{aligned}
& \text { [...] o termo 'Contação de } \\
& \text { histórias' não existe } \\
& \text { gramaticalmente. o } \\
& \text { termo é uma expressão } \\
& \text { relativamente recente, } \\
& \text { livremente traduzida e } \\
& \text { adaptada de países de } \\
& \text { língua castelhana } \\
& \text { "cuentacuentos", que } \\
& \text { pode significar tanto o } \\
& \text { ato de se contar } \\
& \text { histórias, quanto o } \\
& \text { próprio contador." na } \\
& \text { língua inglesa, temos o } \\
& \text { termo "Storytelling" que } \\
& \text { é o ato, ou capacidade de } \\
& \text { se narrar um fato, ou } \\
& \text { história, de improviso, ou } \\
& \text { planejadamente, usando } \\
& \text { diversos tipos de } \\
& \text { recursos, ou um apenas. } \\
& \text { Os termos que se } \\
& \text { encontram fora do uso } \\
& \text { oficinal da língua, mesmo } \\
& \text { que nela não encontrem } \\
& \text { referência nos } \\
& \text { dicionários e acordos } \\
& \text { ortográficos, sim, fazem } \\
& \text { parte da nossa língua, } \\
& \text { desde que não seja um } \\
& \text { erro ortográfico, ou de } \\
& \text { construção verbal } \\
& \text { (TORRES; TETTAMANZY, } \\
& \text { 2008, p. 5). } 5 \text { a }
\end{aligned}
$$

As primeiras produções infantis foram realizadas pelos profissionais da educação no fim do século XVII e durante todo o século XVIII.
Assim, Coelho (1984, p. 31) afirma que "estudar a história é ainda escolher a melhor forma ou o recurso mais adequado de apresentá-la".

Desde a pré-história até os dias de hoje, há a necessidade de descobrir o sentido da vida, buscando interpretações para as inquietações, transmitindo conhecimento dos antepassados para as novas gerações, o que impulsiona a necessidade de ouvir, contar e recontar histórias.

De Acordo com Coelho (1984), o ato de contar histórias, muito antes da invenção da escrita, era o jeito mais importante de passar uma informação adiante. Tudo que uma cultura precisava preservar, suas crenças, sua história e suas tradições tinha que ser contado oralmente, ato este conhecido como tradição oral. Em algumas culturas apenas os contadores podiam usar essa metodologia de contar e passar tradições e crenças oralmente. Os bons contadores precisavam ter boa memória e utilizavam-se de estratégias interessantes para contar suas histórias, assim as pessoas nunca esqueciam-nas. Muitas vezes, essas histórias eram contadas de forma ritmada, assim tornavam-se mais fáceis de serem lembradas.

Pontes (2010) comenta que a literatura de cordel se desenvolveu no nordeste do Brasil, estando presente até hoje. Segundo o autor, as histórias têm sempre seu início nos poemas cantados. O cordelista vai improvisando seus versos e de forma rimada, constrói-se as histórias, e somente depois viram livros impressos para serem colocados à venda em um cordão, o que define a literatura de cordel. Para que os livros sejam vendidos, o vendedor precisa ir cantando as histórias, acompanhado de um instrumento musical, geralmente uma viola.

As histórias narradas por uma determinada população vão ganhando novas versões com o tempo. Um bom contador de histórias pode modificar uma história com o intuito de aprimorá-la ou pelo fato de ter esquecido uma parte dela, acaba inventando algumas partes, fazendo uma nova versão.

A tradição oral é diferente da escrita e não é criada por somente uma pessoa. Ela necessita de toda uma cultura para remodelar uma história, que vai se reformulando a cada geração. Na maioria das vezes, as histórias só passam a ser escritas muito depois que foram criadas e transmitidas oralmente. 
Segundo Scholes e Kellogg (1977),

Enquanto um homem tem a capacidade de criar uma nova habilidade, outro a tem para julgar se ela será bênção ou maldição para seus usuários. Você não inventou um medicamento para fortalecer a memória, mas um substituto inferior para ela. Você está proporcionando aos seus alunos uma maneira de parecem sábios sem verdadeira sabedoria (SCHOLES; KELLOGG, 1977, p. 12).

Pode-se dizer que não existe uma sociedade que não apresente a necessidade de fabular, de inventar-se ou de construir seus mitos e seu imaginário. Toda civilização que existiu contou. A nossa sociedade é mecanicalizada, e a contação de histórias nos faz refletir sobre qualidades e morais já não muito presentes no cotidiano. Porém, até hoje são valorizados os conhecimentos transmitidos pela oralidade em que se redescobre 0 significado das experiências coletivas. Nesse sentido, Meireles (1979) destaca que:

o ofício de contar histórias é remoto [...] e por ele se perpetua a literatura oral, comunicando de indivíduo a indivíduo e de povo a povo o que os homens, através das idades, têm selecionado da sua experiência como mais indispensável à vida (MEIRELES, 1979, p. 41).

O costume de ser ouvinte de histórias desde muito pequeno auxilia na formação da identidade, pois, no momento da contação, estabelece-se uma relação de troca entre contador e ouvintes, o que faz com que toda história cultural e afetiva destes volte à tona, levando-os a ser quem são. "Contar histórias é uma arte porque traz significações ao propor um diálogo entre as diferentes dimensões do ser" (BUSATTO, 2003, p. 10).

Coelho (1984) afirma que as crenças sobre deuses relacionadas à religião são chamadas de mitos, e que estes dizem como um povo acredita ou acreditou um dia, podendo explicar a origem do mundo ou como as pessoas surgiram, como nasce o arco-íris, o sol, o mar, etc. Na tradição esotérica asiática acredita-se que as histórias guardam muita sabedoria. Por esse motivo, toda vez que acreditavam que uma pessoa poderia estar "louca", chamavam um contador de histórias para acalmá-la.

Os contos folclóricos também surgem em diversas culturas, podendo ser muito parecidos com os mitos. Eles podem causar medo, contar uma aventura, serem engraçados, etc. Alguns contos narram histórias sobre heróis poderosos ou sobre trapaceiros espertos que enganam outros personagens, ou ainda contos que falam sobre caipiras, ladrões, fantasmas, bruxas, animais que falam. As histórias que sempre apresentam elementos como paixão, mistério e aventura estão presentes na coletânea das "Mil e Uma Noites", na qual a personagem Sherazade "curou" o coração do sultão" (SCHOLES; KELLOGG,1977).

As cantigas infantis, parlendas, quadrinhas, contos de fadas, fábulas e algumas brincadeiras com as palavras fazem parte dos contos folclóricos. A fábula ensina uma lição sobre o comportamento adequado das pessoas com a utilização de personagens animais que falam e que apresentam comportamentos parecidos como de uma pessoa. "Os contos de fadas falam sobre seres mágicos como fadas, bruxas, dragões e duendes, entre outras criaturas fantásticas" (BETTELHEIM, 2002, p. 152).

Um jeito de entreter as crianças com versos curtos são parlendas ou os trava-línguas que as pessoas vêm usando há séculos, proporcionando momentos prazerosos e lúdicos para uma aprendizagem significativa.

Os acalantos e os chamados brincos são as brincadeiras musicais que fazem parte do começo da vida de qualquer criança. Os adultos usam-nos para adormecer bebês e tranquilizar crianças pequenas; para entretêlas e animá-las. Entre os brincos, os adultos usam "Serra, serra, serrador, serra o papo do vovô", dentre outras variações possíveis de serem encontradas em toda parte do país. Este brinco é cantado enquanto se imita o movimento do serrador. "Palminhas de guiné, pra quando papai vier...", "Dedo mindinho, seu vizinho, maior de todos...", "Upa, upa, cavalinho..." (domínio popular) são exemplos 
de brincos que, espontaneamente, os adultos realizam junto aos bebês e crianças (BRASIL, 1998).

O Referencial Nacional para a Educação Infantil (RCNEI) ainda ressalta que as parlendas propriamente ditas e as mnemônicas são rimas sem música. Usam-se as parlendas como os seguintes exemplos: "Rei, capitão, soldado, ladrão, moço bonito do meu coração..."; "Lá em cima do piano tem um copo de veneno, quem bebeu morreu, o azar foi seu...". Os trava-línguas são parlendas caracterizadas por sua pronunciação difícil: "Num ninho de mafagafos/ Seis mafagafinhos há/ Quem os desmafagafizar/ Bom desmafagafizador será...", ou "Nem a aranha arranha o jarro, nem o jarro arranha a aranha..." (BRASIL, 1998).

As mnemônicas (conjunto de técnicas utilizadas para auxiliar o processo de memorização) referem-se a conteúdos específicos, destinados a fixar ou ensinar algo como número ou nomes. Um exemplo seria: “Um, dois, feijão com arroz/ Três, quatro, feijão no prato/ Cinco, seis, feijão inglês/ Sete, oito, comer biscoito/ Nove, dez, comer pastéis", esboços ou improvisações, ou também na forma de jogos lúdicos ou brincadeiras (BRASIL, 1998).

De acordo com Rodrigues (2005),

A contação de histórias é própria de incentivo para imaginação e o entrelace entre o real e o fictício. Ao pensar em uma história para ser contada, faz-se necessário a tomada de experiência do narrador $\mathrm{e}$ de cada personagem como nossa e ampliamos nossa experiência vivencial por meio da narrativa do autor. Os fatos, as cenas e os contextos são do plano do imaginário, mas os sentimentos e as emoções transcendem a fiç̧ão e se materializam na vida real. (RODRIGUES, 2005, p. 4).

A contação de histórias está ligada diretamente ao imaginário infantil. $\mathrm{O}$ uso dessa ferramenta incentiva não somente a imaginação, mas também o gosto e o hábito da leitura; muitas coisas acontecem ao usar a contação de histórias como, por exemplo, a ampliação e variação do vocabulário, conjunto de elementos que auxiliará no desenvolvimento do das estruturas referentes ao consciente e subconsciente infantil, a diferença que ele fara entre o espaço íntimo do indivíduo, com o mundo social, resultando na formação de valores, personalidade e crenças.

Para Meireles (1979),

$$
\begin{aligned}
& \text { [...] é a Literatura } \\
& \text { Tradicional a primeira a } \\
& \text { instalar-se na memória da } \\
& \text { criança. Ela representa o } \\
& \text { seu primeiro livro, antes } \\
& \text { mesmo da alfabetização, e } \\
& \text { o único, nos grupos sociais } \\
& \text { carecidos de letras. Por } \\
& \text { esse caminho, recebe a } \\
& \text { infância a visão do mundo } \\
& \text { sentido, antes de } \\
& \text { explicado; do mundo } \\
& \text { ainda em estado mágico } \\
& \text { (MEIRELES, 1979, p. 66). }
\end{aligned}
$$

Durante a contação de histórias transmitem-se conhecimentos, sendo que seu planejamento contribui para a formação e no desenvolvimento do processo ensino e aprendizagem. As histórias são uma maneira mais significativa que a humanidade encontrou para relatar as experiências, uma vez que nas narrativas realistas, isso não acontece. A contação de histórias pertence à área das ciências humanas e também ao campo da educação, sendo uma atividade de comunicação (BRASIL, 1998, p.15).

$$
\begin{aligned}
& \text { Por meio dela, os } \\
& \text { homens repassam } \\
& \text { costumes, tradições e } \\
& \text { valores capazes de } \\
& \text { estimular a formação do } \\
& \text { cidadão. Por isso, contar } \\
& \text { histórias é saber criar um } \\
& \text { ambienter de } \\
& \text { encantamento, suspense, } \\
& \text { surpresa e emoção, no } \\
& \text { qual o enredo e os } \\
& \text { personagens ganham } \\
& \text { vida, transformando } \\
& \text { tanto o narrador como o } \\
& \text { ouvinte. O ato de contar } \\
& \text { histórias deve impregnar } \\
& \text { todos os sentidos, } \\
& \text { tocando o coração e } \\
& \text { enriquecendo a leitura } \\
& \text { de mundo na trajetória }
\end{aligned}
$$


de cada um (BUSATTO, 2003, p. 87).

O Referencial Curricular Nacional da Educação infantil relata que a atividade de imaginar possibilita que o ser humano seja capaz de criar uma habilidade de entendimento e compreensão de histórias ficcionais, pois nossa vida apenas é entendida dentro de narrativas. As diferentes histórias transmitem muitas informações que chegam a abranger nossas emoções. As histórias têm um papel significativo, pois contribuem para 0 desenvolvimento do senso de justiça social e também de tolerância, proporcionando-nos criar novos rumos à imaginação, podendo ser eles bons ou ruins. Foi necessário fazer uma reformulação na literatura infantil para que a sua função social pudesse estar dentro dos critérios, respeitando as especificidades e necessidades da intencionalidade que a história tem e se transmite para uma criança (BRASIL, 1998).

\section{A Importância da Contação de Histórias na Educação Infantil}

A educação infantil apresenta uma rotina em que geralmente a contação de histórias está presente, uma vez que este tema está proposto no Referencial Curricular Nacional para a Educação Infantil (RCNEI), elaborado em 199, pelo Ministério da Educação e Cultura (MEC).

Muitos professores não fazem ainda uso da contação de histórias, desconhecendo o quanto ela pode contribuir para a formação do aluno. Quando a usam, apenas o fazem para tranquilizar as crianças, não vendo as muitas possibilidades de uma história boa. O principal objetivo em contar uma história é divertir e estimular a imaginação, mas pode atingir outros objetivos, tais como: educar, instruir, conhecer melhor os interesses pessoais, desenvolver o raciocínio, podendo ser o ponto inicial para desenvolver algum conteúdo do currículo, aumentando o interesse pela aula ou permitindo a auto-identificação, auxiliando na compreensão de situações adversas e resolvendo conflitos (VILLARDI, 2005).

$$
\begin{aligned}
& \text { Chegaram ao seu coração } \\
& \text { e à sua mente, na } \\
& \text { medida exata do seu } \\
& \text { entendimento, de sua } \\
& \text { capacidade emocional, }
\end{aligned}
$$

porque continham esse

elemento que a

fascinava, despertava o

seu interesse e

curiosidade, isto é, o

encantamento, o

fantástico, $\quad 0$

maravilhoso, o faz de

conta (ABRAMOVICH,

1997, p. 37).

Durante as contações de histórias acontecem momentos mágicos que mobilizam a todos que fazem parte dessa atividade. Nas narrações, os professores estabelecem com os educandos um clima de envolvimento que os fazem lembrar da época dos primeiros contadores que se reuniam em volta do fogo e contavam para pessoas atentas às diversas histórias, sobre os costumes e valores daquele povo. Os espectadores não ficam mais em torno da fogueira, e nas escolas, são os professores os contadores de história, sendo o elo entre o aluno e o livro.

Em relação a isto, Pennac (1993, p. 124) discorre afirmando que " $O$ ato de contar histórias é próprio do ser humano, e o professor pode apropriar-se dessa característica e transformar a contação em um importantíssimo recurso de formação do leitor".

Podemos citar um grande número de possibilidades que a contação de histórias propicia em sala de aula. Servindo para divertir, educar, instruir, socializar, desenvolver a inteligência e a sensibilidade. A literatura não está recebendo um estímulo adequado.

Sekeff (2007) comenta que a contação de histórias possibilita aos educandos uma experiência positiva com o universo da leitura, não podendo ser uma tarefa rotineira que transforma a leitura em um instrumento de avaliação, fazendo com que os alunos se afastem do prazer de ler. Essa prática é necessária para formar grandes leitores críticos, não bastando somente ensinar a ler, mas também ensinar a gostar de ler, a ler com prazer. Segundo Ruan Hubert,
no primeiro ano de vida
os interesses da criança
são especificamente
orgânico-afetivos; entre
um e três anos esses
interesses rão
governados 
movimento, percepção e linguagem; dos três aos sete anos, lidera o movimento lúdico, o jogo em geral, imagens, ficções e mitos (SEKEFF, 2007, p. 121).

Ao utilizar as diferentes narrações em aula, todos saem ganhando, tanto o aluno, que terá a possibilidade de imaginar e criar, quanto o educador, que fará de suas aulas mais produtivas num ambiente mais agradável, alcançando os objetivos pretendidos. Uma vez usando essa estratégia, os alunos ampliarão o contato com os diferentes materiais impressos, expandindo-se o universo cultural e imaginário.

Com as diferentes estratégias, a contação de histórias pode trazer descobertas, intrigar, provocar o riso, fazer pensar, ficar perplexo, encantado, etc. Para se contar uma história, é necessário percorrer um caminho infinito de descobertas e compreensão sobre o mundo. As narrativas despertam em quem ouve a emoção, imaginação e o gosto pela escrita e pela leitura, uma vez que contar histórias é trazer à tona segredos, envolver o ouvinte e convidá-lo a se apaixonar pela leitura.

Para Abramovich (1997, p. 35) "A contação de história é fonte inesgotável de prazer, conhecimento e emoção, em que o lúdico e o prazer são eixos condutores no estímulo à leitura e à formação de alunos leitores".

Nesse sentido, Miguez (2000) discursa destacando que:

A alegria proporcionada pelas histórias deveriam ser a principal dimensão da pedagogia, visto que os alunos necessitam de estímulos e motivações para que possam se interessar pelos conteúdos, sendo assim as aprendizagens ficariam mais significativas (MIGUEZ, 2000, p.125).

Sabe-se que no cotidiano da Educação Infantil as contações de histórias vêm atendendo a diversos propósitos, sendo impossível pensar nessa modalidade da educação básica sem a utilização desta prática.

É notório que a contação de histórias é uma atividade praticada cada vez mais na escola, desenvolvida a partir do planejamento do professor, da visita planejada de um contador pela instituição escolar ou pela elaboração de espaços culturais, como feira do livro, bibliotecas, cantinhos de leitura, etc. O professor, por meio de sua formação, tem contato com diversas possibilidades de integração da literatura em sua rotina.

Segundo Abramovich (1997), ao considerar a contação de histórias como portadora de significados para a prática pedagógica, não se restringe o seu papel somente ao entendimento da linguagem, pois preserva-se seu caráter literário, sua função de despertar a imaginação e sentimentos, assim como suas possibilidades de transcender a palavra.

A ação de contar histórias deve ser utilizada dentro do ambiente educacional, não somente pelo lado lúdico, muitas vezes exercitado em momentos estanques da prática, como a hora da história, mas incluí-la na sala de aula como metodologia que favorece a prática docente, promovendo aprendizagens múltiplas de diversos conhecimentos.

$\mathrm{Na}$ maioria dos casos, a Escola acaba sendo a única fonte de contato da criança com o livro e, sendo assim, é necessário estabelecerse um compromisso maior com a qualidade e o aproveitamento da leitura como fonte de prazer. (MIGUEZ, 2000, p. 28).

Nesse sentido, evidenciamos que a contação de histórias deve ser usada como mecanismo e metodologia para o desenvolvimento dos alunos e de sua personalidade, melhorando de maneira significativa o desempenho escolar.

Muitos teóricos como Busatto (2003), Miguez (2000), Bettelheim 2002) falam sobre a questão da relevância dos textos literários no período de escolarização.

"É importante e complicado a tarefa de criação das crianças, a qual consiste em ajudá- 
las a encontrar significado na vida" (BETTELHEIM 2002, p. 11). Em primeiro lugar, o autor coloca o impacto dos pais nessa tarefa; e, em segundo lugar, cita a herança cultural transmitida de maneira correta, dizendo que "Quando as crianças são novas, é a literatura que canaliza melhor este tipo de informação". Em relação à leitura em si, ele acrescenta que " $A$ aquisição de habilidades, inclusive a de ler, fica destituída de valor quando o que se aprendeu a ler não acrescenta nada de importante à nossa vida (BETTELHEIM, 2002, p. 12).

Bettelheim (2002) acredita que é estimulando os educandos a criar, imaginar, envolver-se, que se dá um grande passo para o enriquecimento e desenvolvimento da personalidade, por isso é de suma importância a utilização do conto. Acredita-se, também, que a contação de histórias pode interferir positivamente para a aprendizagem significativa, pois o fantasiar e o imaginar antecedem a leitura. Utiliza-se da leitura, por meio da contação de histórias, como instrumento metodológico para favorecer desenvolvimento dos alunos e melhoria de seu desempenho escolar, respondendo a necessidades afetivas e intelectuais pelo contato com o conteúdo simbólico das leituras trabalhadas.

\section{Estratégias e estruturas para contação de histórias}

O que é imprescindível a uma sessão de contação de histórias, mesmo que o ambiente seja simples, é a presença de elementos que façam dele um lugar diferenciado para essa atividade. Uma organização adequada para envolver as crianças nesse tipo de atividade depende do local e dos materiais que devem estar de acordo com o texto e também a preparação de quem irá contá-la. Portanto, a decisão sobre como escolher e preparar esse lugar, certamente, levará em conta vários detalhes.

Sisto (2009) diz que algumas vezes as histórias são lidas diretamente do livro, mas que quando se decide não utilizar esse recurso incorpora-se o espírito de contador de histórias em sua plenitude. É necessário deixar claro que o livro estará e deverá sempre estar presente. A diferença é que, ao reduzir ou deixar de consultá-lo com muita frequência ao longo das histórias, o contador abre espaço para a utilização de técnicas próprias do mistério que é de contar histórias, além de abrir caminho para a sua criatividade. Sempre será possível fazer uma adaptação ao realizar uma releitura do texto, de acordo com as circunstâncias da comunicação oral.

Torres e Tettamanzy (2008) comentam que o modo como as pessoas, principalmente os pais e professores apresentam as histórias, desperta ou inibe a curiosidade, o interesse e o prazer em ouvi-las, tornando sempre um desafio para quem vai contá-las, pois é preciso investir não apenas no preparo, mas em todos os detalhes que podem ser agregados durante o percurso desse trabalho.

Segundo Otte e Kovàcs (2003), os incentivos e estímulos para que se possa contar uma narrativa são variados, mas para funcionar irão depender de como o contador direcionará todas as informações. Não existe nenhuma estratégia milagrosa que substitua o comprometimento do contador. Quem tiver a pretensão em ser um contador de histórias melhor, deve elaborar algumas estratégias importantes em sua preparação.

Nesse sentido, o contador deve memorizar a história a ser contada e apresentada, familiarizando-se com cada parágrafo do livro para não perder "o fio da meada"; destacar e sublinhar os tópicos mais importantes, interessantes e significativos com gestos e variações de voz de acordo com cada personagem; vivenciar a vivenciar a história e envolver-se com ela; atrair os ouvintes para a magia da história; oferecer espaço aos ouvintes que querem interferir na história e participar dela; respeitar as pausas, perguntas e comentários naturais que a história possa despertar, tanto em quem lê quanto em quem ouve; deixar a alegria e o prazer provocados pelas histórias transparecerem para atingir os ouvintes (OTTE; KOVÀCS, 2003).

Segundo Abramovich (1997, p. 125), "o ouvir histórias pode estimular o desenhar, o musicar, o sair, o ficar, o pensar, o teatrar, o imaginar, o brincar, o ver o livro, o escrever, o querer ouvir de novo. Afinal, tudo pode nascer dum texto!". A criança, ao ouvir histórias, vive todas essas emoções. Afinal, escutar histórias é o início, para tornar-se um leitor, um inventor, um criador.

Já em relação ao local e o espaço físico para a contação de história, Vieira (2013) diz que é muito importante, pois interfere não apenas na desenvoltura do contador de 
histórias, mas também em como os ouvintes receberão o conteúdo. Alguns dos aspectos que devem ser considerados dizem respeito à acomodação da plateia e quais características ambientais colaboram para a encenação e o conforto de todos. "Se o lugar é ao ar livre, deverá se procurar uma árvore ou pedra que sirva de fundo. Em espaços fechados, preferivelmente, as crianças devem ser posicionadas em semicírculo" (VIEIRA, 2013, p. 59).

Minami (2012) afirma que a contação de histórias deve ser realizada próxima às crianças. Além disso, é preciso protegê-las de fatores que prejudicam a comunicação, como janelas e espelhos atrás do contador de histórias ou ambiente afetado pela presença de ruídos indesejáveis, onde a acústica será um dos elementos que não pode ser esquecido. Uma das formas mais indicada para dispor os ouvintes é em semicírculo. Mesmo assim é necessário que se confirme todos os elementos citados anteriormente, inclusive prever os imprevistos.

Villardi (2005) disserta sobre a importância dos recursos materiais utilizados para a contação de histórias, destacando que:

[...] a leitura é o meio mais importante para se chegar ao conhecimento. Não importa a quantidade que lemos o que importa é com que profundidade chega-se a esse entendimento. É recomendável ser bastante criativo no uso de recursos materiais (VILLARDI, 2005, p.59)

Não se pode ficar somente preso a certos padrões, mas sempre é necessário variar de acordo com o público e com o assunto da história a ser contada, modificando os materiais utilizados que, segundo Otte e Kovàcs (2003), podem ser o flanelógrafo para ilustrar uma narrativa com diversos assuntos ou simbolismos; as transparências confeccionadas pelas crianças para despertar o interesse e auxiliar na memorização da história; os slides com figuras da história despertam as fantasias para prender a atenção e concentração das crianças; os bichos de pelúcia e os fantoches para pequenas encenações; a massinha de modelar para a confecção de elementos ou personagens da história que ouviram; materiais colhidos na natureza pelas crianças, valorizando assim a sua participação; narrar histórias em museus, cemitérios com antigas sepulturas ou simplesmente convidar uma pessoa mais idosa para narrar sua história falando do passado.

Existem infinitas possibilidades que podem ser exploradas. Nesse momento histórico que vivemos, o educador precisa transformar sua sala em um local prazeroso e estimulante, fazendo uso das diferentes situações para que o aluno e ouvinte possam desenvolver livremente a compreensão e fazer questionamentos a partir da leitura de uma vasta literatura. Também é motivo de orgulho para o professor confirmar e poder sentir que os alunos foram motivados pelos livros e que com seu trabalho formou leitores críticos e criativos, sendo capazes de ler e reler, contando e recontando, analisando e interpretando qualquer tipo de texto, podendo ser ele pedagógico, formativo ou simplesmente pelo prazer com o auxílio de alguns objetos do cotidiano, como faca, garfo, copo, como passava a um tempo atrás na TV Cultura.

A cada história narrada para uma criança produz-se emoções e provoca-se reações. Por isso, segundo Arruda (2011), para a criança de 8 a 10 anos de idade, os mundos da fantasia e realidade se confundem por se fundirem. Os sentimentos e também os pensamentos das crianças estão em permanente transformação e ebulição. Isso acontece inconscientemente e acabam procurando respostas para certos anseios e medos (SISTO, 2005).

Corroborando a ideia deste autor, Pennac (1993) destaca que:

Qualquer história pode
atingir uma criança
profundamente e fazer
com que ela peça a
repetição dessa história
durante dias e mesmo
semanas, porque algo na
essência de reu
desenvolvimento ro
amadurecimento foi
atingido (PENNAC, 1993,
p.86).

Quadros e Rosa (2009) fez uma préseleção de temas que podemos contar de acordo com a idade e série que a criança está 
sendo mais atrativos para as crianças de até três anos os temas: Histórias de bichos e Contos rítmicos que sejam leves, lúdicos, bemhumorados e curtos. Já para a fase pré-mágica (crianças de 3 a 5 anos), os olhares já se voltam para histórias que tenham bichos ou contos de fadas pequenos com poucas personagens e enredo mais simples, pequenos poemas, parlendas e trava-línguas.

No ensino fundamental, a partir dos seis anos as crianças já buscam histórias de crianças, animais e encantamentos, contos de fadas mais elaborados, aventuras no ambiente próximo: família e comunidade. Aos oito e nove anos já estão em sua grande maioria alfabetizadas, compreendendo mais 0 universo, buscando histórias humorísticas, contos de fadas mais elaborados, lendas folclóricas, mitos e histórias verídicas (QUADROS; ROSA, 2009).

Ao entrarem em uma fase que se aproxima da adolescência, a partir dos dez anos, os assuntos que mais os interessam são narrativas de viagens, mitos (persas, hindus, árabes e egípcios), histórias verídicas, romances e biografias (QUADROS; ROSA, 2011).

Arruda (2011) sugere algumas técnicas para contar e encantar. Destaca-se o olhar nos olhos dos ouvintes, como se estivesse contando somente para ele. Não se deve flutuar o olhar sobre os ouvintes, o olhar do contador deve estar atento aos olhos das pessoas, fazendo com que eles se sintam atraídos pela historia.

A voz é o elemento principal da narração oral, merecendo uma atenção à parte. É importante observar a dicção que deve ser impecável, pronunciando-se todas as letras de cada palavra. É necessário evitar uma pronúncia muito devagar, as pausas são necessárias, mas cuidando sempre para que não sejam prolongadas (ARRUDA, 2011).

Começar com um pequeno diálogo antes das histórias, explicando o porquê da escolha do tema, quem escreveu a narrativa e se o tema gerador está presente em algum acontecimento importante (ARRUDA, 2011).

Como explica Amaral e Miller (2008):

[...] O contador tem o aval de para contar a história a seu modo, com formulações próprias, muitas vezes introduzindo expressões próprias da decorrer do processo. Isso não é melhor nem pior do que ler história: cada ação tem sua contribuição a dar. O importante é que sejam desenvolvidas em sala de aula com as crianças (AMARAL; MILLER, 2008, p. 159).

Busatto (2003) destaca que repetir a história faz bem para as crianças principalmente para as menores, entre um e seis anos, que muitas vezes solicitam o reconto da mesma várias vezes. $E$ quando isso acontece, reforçamos as imagens e mensagens da história, criando uma segurança linguística. Além disso, contribui para a construção do vocabulário infantil que sempre está aumentando. Toda vez que recontamos a mesma história, ela será compreendida e vivenciada de uma forma totalmente diferente a cada nova apreciação.

A duração pertinente de cada história irá depender do número de ouvintes, da idade e da técnica a ser escolhida para essa contação. Provavelmente as crianças manterão o mesmo tempo de atenção e concentração que ficam para outras atividades similares, tais como: brincar com objetos; folhear revistas em quadrinhos; brincar de pega-pega, etc (BUSATTO, 2003).

Nessa ótica, Rodrigues (2005) reforça que podemos remodelar as histórias, adaptando-as à faixa etária, pois algumas delas não são adequadas, podendo até mesmo traumatizar as crianças que nesta idade fazem muito silogismo à vida real. Já as crianças maiores conseguem lidar melhor com as diferentes situações, não se traumatizam com os fatos, que muitas vezes são iguais, ou até mesmo mais suaves do que já vivenciaram com sua família.

Rodrigues (2005) comenta que mostrar ou não mostrar as ilustrações de um livro dependerá da proposta e dos objetivos do professor. Na grande maioria das vezes é quase impossível não mostrar. Se a história utiliza o livro como apoio, o professor deve estabelecer regras antes do início da leitura, podendo mostrar antes, durante ou ao término da contação.

Quadros e Rosa (2009) e Sisto (2005) dizem que histórias de medo contadas antes 
do processo de dormir podem atrapalhar o sono. Um exemplo são os adultos e adolescentes que, quando assistem a filmes ou algumas cenas mais fortes no fim da noite, acabam tendo pesadelos ou isso acaba ocasionando dificuldade para pegar no sono. Por esse motivo, as histórias para dormir precisam ser mais tranquilas e de preferência extensas para estimular o processo do sono. No entanto é muito saudável contar essas histórias no começo da noite, quando ainda vai demorar para dormir, para sobrar tempo para outras brincadeiras e assim dominar ou distrair os possíveis medos e receios que a ela possa ter estimulado.

Para Scholes e Kellogg (1977), as histórias ajudam no comportamento das crianças, por isso quanto mais novas, menos experiências afetivas, sociais e conhecimentos elas possuirão. As histórias ajudam nas descobertas de ações e atitudes, dando exemplos bons e ruins de possíveis consequências sobre os atos que os personagens podem fazer. Mesmo sem explicações, as crianças percebem as escolhas de cada personagem e, por isso, distinguem o certo e o errado ou fortalecem atributos positivos como: determinação, compaixão, força de vontade e outros sentimentos.

\section{CONSIDERAÇÕES FINAIS}

A escola é um ambiente de construção e reconstrução de conhecimentos e, como tal, deve dar especial atenção à contação de histórias, pois ela contribui na aprendizagem escolar em todos os aspectos: cognitivo, físico, psicológico, moral ou social, proporcionando um maior desenvolvimento perceptivo no aluno. Sobre suas vantagens, foram destacadas a aprendizagem de conteúdos, a socialização, a comunicação, a criatividade e a disciplina, aprender de forma lúdica e prazerosa.

Tomamos conhecimento do desafio que é proposto ao contar histórias, mas também que é possível desenvolver um trabalho com uma diversidade incrível de propostas na área da linguagem.

O trabalho com as histórias na Educação Infantil é um desafio frequente, tanto para organizar e desenvolver o currículo que atenda a todos, quanto à disponibilidade de repensarmos nosso trabalho nessa modalidade de ensino, num processo de reflexão sobre os nossos objetivos, os recursos materiais, ou seja, a nossa prática como um todo.

Ser contador e ouvinte de histórias remete a essa maravilhosa e prazerosa prática da oralidade, proporcionando a quem ouve uma oportunidade envolvente para desenvolver e enriquecer a imaginação, o vocabulário e vivenciar experiências. $\mathrm{Na}$ formação de uma criança, ouvir histórias é o primeiro passo da aprendizagem para se tornar um leitor, e sendo leitor irá ter um caminho infinito de descobertas e compreensão do mundo. $O$ orador irá trabalhar a linguagem oral, possibilitando caminhos para que aprendamos a falar, ler e escrever e também a pensar melhor.

Sempre se faz necessário aprendermos novas técnicas ou simplesmente olhar os nossos alunos sabendo que eles são capazes em suas singularidades de aprender a seu próprio modo e tempo, rever nossas expectativas de professores, nossa forma de avaliar, melhorando a relação entre professor/aluno.

Cabe a nós, professores, o compromisso de garantir uma educação de qualidade, pois somos responsáveis pelo bom desempenho de todos os alunos que atendemos diariamente em nossas salas de aula.

Foi possível concluir que a literatura juntamente com a prática da contação de história representa um vasto "leque" de possibilidades dentro das salas de aula, desenvolvendo não somente a linguagem, como também auxiliando na elaboração e produção de bons textos, criando possibilidades pedagógicas diversificadas, criativas e estimulantes para desenvolver a atenção e a concentração dos alunos. Toda literatura bem contada, por mais simples ou curta que possa parecer, contribui para algo a mais no repertório da criança, auxiliando o desenvolvimento de uma forma criativa, diferente e reflexiva, proporcionado pela oralidade uma riqueza extraordinária que irá permitir organizar todas as outras habilidades.

\section{REFERÊNCIAS}

ABRAMOVICH, F. Literatura infantil: gostosuras e bobices. São Paulo: Scipione, 1997.

AMARAL, S. M.; MILLER, S. Desenvolvimento da linguagem oral e escrita. Curitiba: PROINFANTI, 2008. 
ARRUDA, E. Qual é a diferença entre ler e contar histórias? Revista Nova Escola, São Paulo, v. 18, n. 242, p. 44-49, jan./fev. 2011.

BETTELHEIM, B. A psicanálise dos contos de fadas. 16. ed. Rio de Janeiro: Paz e Terra, 2002.

BRASIL. Ministério da Educação e do Desporto. Secretaria de Educação Fundamental Referencial curricular nacional para a educação infantil. Brasília: MEC/SEF, 1998.

BUSATTO, C. Contar \& encantar: pequenos segredos da narrativa. Rio de Janeiro: Vozes, 2003.

CERVO, A. L; BERVIAN, P. A; SILVA, R. da. Metodologia científica. 6. ed. São Paulo: Pearson Prentice Hall, 2007.

COELHO, N. N. A literatura infantil: história, teoria, análise. 3. ed. São Paulo: Quíron, 1984.

CRUZ, V. A. G. da. Pesquisa em educação: pedagogia. São Paulo: Pearson Prentice Hall, 2011.

MEIRELES, C. Problemas da Literatura Infantil. São Paulo: Summus, 1979.

MILLER, S.; AMARAL, S. A. O desenvolvimento da linguagem oral e escrita em crianças de 0 a 5 anos. Curitiba: PróInfantil, 2008.

MIGUEZ, F. Somos todos leitores. Curitiba: PróInfantil, 2000.

MINAMI, T. A arte dos contadores de histórias. Revista Nova Escola, São Paulo, v. 22, n. 254, p. 35-42, jan./fev. 2012.

OTTE, M. W.; KOVÁCS, A. A magia de contar histórias. Revista Leonardo Pós-órgão de Divulgação Científica e Cultural do ICPG, Blumenau, v. 1, p. 17-21, 2003.

PENNAC, D. Como um romance. Rio de Janeiro: Rocco, 1993.

PONTES, M. A. A literatura de cordel como fonte de incentivo no ensino de literatura. Revista Pedagogia ao Pé da Letra, Pernambuco, v. 2, n.16, p.32, 2o sem., 2010.
QUADROS D.; ROSA, V. M. C. D. Formar Leitores é um desafio para a escola. Revista Chão da Escola, Rio de Janeiro, v.12, n. 8, p. 19-26, nov., 2009.

RODRIGUES, E. B. T. Cultura, arte e contação de histórias. Goiânia: Gwaya, 2005.

TORRES, S. M.; TETTAMANZY, A. L. L. Contação de histórias: resgate da memória e estimulo à imaginação. Revista Eletrônica de Crítica e Teoria de Literaturas, Porto Alegre, v. 4, n. 1, p 25-32, jan./jun. 2008.

VIEIRA, I. M. de C. O papel dos contos de fadas na construção do imaginário infantil. Revista Criança do professor de educação infantil, Brasilia, v. 1, n.38, p.5, abr., 2013.

VILLARDI, R. Ensinando a gostar de ler: formando leitores para a vida inteira. Rio de Janeiro: Qualitymark, 2005.

SCHOLES, R.; KELLOGG, R. A natureza da narrativa. São Paulo: MCGRawHill do Brasil, 1977.

SEKEFF, M. de L. Da música: seus usos e recursos. São Paulo: Ed. UNESP, 2007.

SISTO, C. A literatura frequenta a escola... Mas quem conta as histórias? In: PAROLIN, I. C. H. (Org.). Sou professor! A formação do professor formador. Curitiba: Positivo, 2009. p. 67-71.

Textos e pretextos sobre a arte de contar histórias. 2. ed. Curitiba: Ed. Positivo, 2005.

Recebido para publicação em: 23/04/2016

Revisado em: 26/04/2016

Aceito em: 29/04/2016 